\title{
Prostaglandin $I_{2}$ analog suppresses lung metastasis by recruiting pericytes in tumor angiogenesis
}

\author{
YOSHINORI MINAMI ${ }^{1}$, TAKAAKI SASAKI ${ }^{1}$, HIROKI BOCHIMOTO $^{2}$, \\ JUN-ICHI KAWABE ${ }^{3}$, SATOSHI ENDO ${ }^{1}$, YOSHIKI HIRA ${ }^{2}$, TSUYOSHI WATANABE ${ }^{2}$, \\ SHUNSUKE OKUMURA $^{1}$, NAOYUKI HASEBE ${ }^{4}$ and YOSHINOBU OHSAKI ${ }^{1}$ \\ ${ }^{1}$ Respiratory Center, Departments of ${ }^{2}$ Microscopic Anatomy and Cell Biology and \\ ${ }^{3}$ Cardiovascular Regeneration and Innovation, and ${ }^{4}$ Cardiovascular, Respiratory and Neurology Division, \\ Department of Medicine, Asahikawa Medical University, Asahikawa, Hokkaido 078-8510, Japan
}

Received July 9, 2014; Accepted September 1, 2014

DOI: $10.3892 /$ ijo.2014.2783

\begin{abstract}
Prostaglandin $\mathrm{I}_{2}\left(\mathrm{PGI}_{2}\right)$ agonist has been reported to reduce tumor metastasis by modifying tumor angiogenesis; however, the mechanisms of how $\mathrm{PGI}_{2}$ affects the endothelial cells or pericytes in tumor vessel maturation are still unclear. The purpose of this study was to clarify the effects of $\mathrm{PGI}_{2}$ on tumor metastasis in a mouse lung metastasis model using Lewis lung carcinoma (LLC) cells. The mice were treated continuously with beraprost sodium (BPS), a $\mathrm{PGI}_{2}$ analog, for 3 weeks and then examined for lung metastases. The number and size of lung metastases were decreased significantly by BPS treatment. In addition, scanning electron microscopy and immunohistochemistry revealed that BPS increased the number of tumor-associated pericytes and improved intratumor hypoxia. Collectively, this study suggests that BPS attenuated vascular functional maturation in metastatic tumors.
\end{abstract}

\section{Introduction}

Prostaglandin $\mathrm{I}_{2}\left(\mathrm{PGI}_{2}\right)$ is an important vascular prostanoid that provides an important balance in tumor angiogenesis $(1,2)$. Honn et al were the first to demonstrate that $\mathrm{PGI}_{2}$ strongly reduced the number of lung tumor metastases using an artificial lung metastasis model (3). Since the initial reports of the anti-metastatic action of $\mathrm{PGI}_{2}$ and its analogs, a wide variety of tumor cell lines have been studied in models of artificial metastasis (4-15). However, the relationship between $\mathrm{PGI}_{2}$-prostacyclin receptor (IP) signaling and tumor

Correspondence to: Dr Takaaki Sasaki, Respiratory Center, Asahikawa Medical University, 2-1-1-1 Midorigaoka-Higashi, Asahikawa, Hokkaido 078-8510, Japan

E-mail: takaaki6@asahikawa-med.ac.jp

Key words: prostaglandin $\mathrm{I}_{2}$, metastasis, maturation, pericytes, hypoxia angiogenesis, including endothelial cells and pericyte interaction, remains to be clarified.

Tumor blood vessels are structurally and functionally abnormal, in that they lack the normal hierarchical arrangement of arterioles, capillaries, and venules (16). Tumor endothelial cells are often loosely connected to each other and are covered by fewer and more abnormal mural pericytes (16-18). In clinical data, low pericyte coverage of tumor blood vessels is related to poor patient prognosis (19-21), and pericyte dysfunction is suggested to increase metastasis (22).

Our recent studies have revealed novel effects of $\mathrm{PGI}_{2}$ on its target cells, such as endothelial and endothelial progenitor cells (23), which suggested that $\mathrm{PGI}_{2}$-IP signaling attenuates vascular maturation through endothelial and pericyte interaction. In this study, we evaluated whether activation of $\mathrm{PGI}_{2}$-IP signals of tumor blood vessels by a stable $\mathrm{PGI}_{2}$ analog, beraprost sodium (BPS), enhanced pericyte adhesion to endothelial cells, induced maturation of tumor blood vessels, decreased hypoxic areas in the metastatic tumors, and resulted in suppression of lung metastasis in lung cancer.

\section{Materials and methods}

Lung cancer cell line and reagents. Lewis lung carcinoma (LLC; non-small cell lung cancer derived from C57BL/6 mice) cells were purchased from American Type Culture Collection (Manassas, VA, USA) and maintained at $37^{\circ} \mathrm{C}$ in $5 \% \mathrm{CO}_{2}$ using RPMI-1640 medium (Life Technologies, Grand Island, NY, USA) containing $2 \mathrm{mM} \mathrm{L}$-glutamine, $50 \mathrm{U} / \mathrm{ml}$ penicillin, and $50 \mu \mathrm{g} / \mathrm{ml}$ streptomycin, supplemented with $10 \%$ fetal bovine serum (complete medium). BPS was provided by Toray Industries, Inc. (Chiba, Japan).

Mouse lung metastasis model. Female C57BL/6 mice, 8- to 10-weeks-old (20-25 g), were obtained from Charles River Laboratories Japan, Inc. (Kanagawa, Japan). LLC cells $\left(5.0 \times 10^{6}\right.$ cells) in $500 \mu \mathrm{l}$ phosphate-buffered saline (PBS) were injected into the tail veins of mice ( 5 mice/group) to generate lung tumor metastases. The day after LLC cell injection, an Alzet mini-osmotic pump (Durect Corp., Cupertino, 
CA, USA) filled with BPS $(20 \mu \mathrm{g} / \mathrm{ml})$ or deionized distilled water (DDW) was implanted under the skin of each mouse. BPS or DDW was continuously administered for 3 weeks. To assess the hypoxic area in metastatic tumors, mice were orally administered $15 \mathrm{mg} / \mathrm{ml}$ Hypoxyprobe-1 (pimonidazole $\mathrm{HCl}$; Hypoxyprobe, Inc., Burlington, MA, USA) $1 \mathrm{~h}$ before sacrifice.

Immunohistochemistry. $\alpha$-SMA (Abcam, Cambridge, UK) and NG2 (Millipore, Billerica, MA, USA) as pericyte markers and Endomucin (Santa Cruz Biotechnology, Inc., Santa Cruz, CA, USA) as an endothelial cell marker were studied by immunofluorescence to evaluate angiogenesis in metastatic lung tumors. Hypoxic areas were evaluated by a Hypoxyprobe-1 kit.

Zinc-fixed lung specimens were sectioned ( $4 \mu \mathrm{m}$ thickness), mounted onto slides, and air-dried for $30 \mathrm{~min}$. The sections were deparaffinized in xylene and rehydrated via a series of graded alcohols. The slides were rinsed with PBS, and antigen retrieval was enhanced by microwaving in $10 \mathrm{mM}$ citrate buffer $\mathrm{pH} 6.0$ for $20 \mathrm{~min}$. They were incubated in $1 \%$ bovine serum albumin + PBS-T (Triton) for $20 \mathrm{~min}$ at room temperature and then incubated overnight at $4^{\circ} \mathrm{C}$ with a $1: 100$ dilution of rabbit anti-mouse $\alpha$-SMA, 1:200 dilution of rabbit anti-mouse NG2, or 1:50 dilution of MAb1 (mouse monoclonal anti-pimonidazole antibody). They were rinsed with PBS and then incubated for $1 \mathrm{~h}$ with a goat anti-rabbit Alexa Fluor 488 antibody (diluted 1:1,000) or a donkey anti-mouse Alexa Fluor 488 antibody (diluted 1:1,000) at room temperature. Slides were rinsed with PBS, incubated for $20 \mathrm{~min}$ in $1 \%$ bovine serum albumin + PBS-T, and then incubated with a 1:50 dilution of rat anti-mouse Endomucin at $4^{\circ} \mathrm{C}$ overnight. Slides were rinsed with PBS and then incubated for $1 \mathrm{~h}$ with a rabbit anti-rat Alexa Fluor 594 antibody (diluted 1:500) at room temperature. After rinsing, slides were incubated with Hoechst 33258 (diluted 1:1,000; Invitrogen Life Technologies, Carlsbad, CA, USA) for $30 \mathrm{~min}$ at room temperature. Slides were mounted with Fluoromount (Diagnostic Biosystems, Pleasanton, CA, USA) to prevent fluorescent bleaching.

Quantification of lung metastasis. Excised mouse lungs were fixed in zinc fixative (BD Biosciences Pharmingen, Inc., San Diego, CA, USA) and embedded in paraffin. Tumor metastasis to the lungs was assessed by hematoxylin and eosin (H\&E) staining. Light photomicrographs of the left lobe of the lungs were taken at magnification, x40 (5 visual fields/section and 5 sections/mouse) using a light microscope (BX51; Olympus, Tokyo, Japan). The number of metastatic nodules was counted, and the metastatic area was quantified using ImageJ software (NIH, Bethesda, MD, USA).

DDW- and BPS-treated mice within an experimental set (5 mice/group) were analyzed with the same threshold and results as reported below. Tumors were selected at random from each slide (4 tumors/mouse and 5 mice/group) at magnification, x200 observed with a fluorescence microscope (BX51; Olympus). The tumor area, number of Endomucin ${ }^{+}$cells in the tumor, and number of $\alpha-\mathrm{SMA}^{+}\left(\right.$or NG2 $2^{+}$)/Endomucin ${ }^{+}$ double-positive cells in the tumor were quantified. Results were reported as number of vessel-associated pericytes per Endomucin ${ }^{+}$cell per tumor area $\left(/ \mathrm{mm}^{2}\right)$. The area of hypoxia was analyzed as described below. Tumors observed with a fluorescence microscope were selected at random from each slide (4 tumors/mouse and 2 mice/group) at original magnification, $\mathrm{x} 200$. The tumor area and area of $\mathrm{MAb1}^{+}$cells in each tumor were quantified by ImageJ software. The result is reported as the ratio of hypoxic area to tumor area.

Scanning electron microscopy. Tissue preparation for scanning electron microscopy, the potassium hydroxide $(\mathrm{KOH})$ digestion method was described previously (24). Anesthetized control and treated mice were perfused with physiological saline followed by a mixture of $0.5 \%$ glutaraldehyde (GA)- $0.5 \%$ paraformaldehyde (PFA) in $0.1 \mathrm{M}$ phosphate buffer solution (PB), $\mathrm{pH}$ 7.4. After fixation by perfusion, lungs were cut and immersed in $2 \% \mathrm{GA}$ in $0.1 \mathrm{M}$ PB for 2 weeks at $4^{\circ} \mathrm{C}$. Then the tissue blocks were washed thoroughly with $0.1 \mathrm{M} \mathrm{PB}$, immersed in $30 \% \mathrm{KOH}$ solution for $8-10 \mathrm{~min}$ at $60^{\circ} \mathrm{C}$ to remove the extracellular matrix around tumor blood vessels. After $\mathrm{KOH}$-digested tissue blocks were rinsed five or six times in $0.1 \mathrm{M} \mathrm{PB}$, they were conductively stained by treating with $1 \%$ tannic acid in $0.1 \mathrm{M} \mathrm{PB}(2 \mathrm{~h}$, $\left.20^{\circ} \mathrm{C}\right)$ and $1 \% \mathrm{OsO}_{4}$ in $0.1 \mathrm{M} \mathrm{PB}\left(2 \mathrm{~h}, 20^{\circ} \mathrm{C}\right)$. After conductive staining, the samples were dehydrated in graded ethanols, transferred to isoamyl acetate, and dried in a critical point dryer (HCP-2; Hitachi Koki Co., Ltd., Tokyo, Japan) using liquid $\mathrm{CO}_{2}$. The dried samples were mounted onto a metal plate, coated with platinum-palladium using an ion-sputter coater (E1010; Hitachi Koki Co., Ltd.), and then observed with a field emission type scanning electron microscope (S-4100; Hitachi High-Technologies Corp., Tokyo, Japan).

Clonogenic growth assay. LLC cells $\left(1.5 \times 10^{3}\right.$ cells) were incubated in 6-well plates for $24 \mathrm{~h}$. Subsequently, growth medium was changed to complete medium containing the indicated concentrations of BPS. Treated cells were incubated under normoxic condition for 10 days. After incubation, colonies in a 6 -well plate were stained with $0.5 \%$ crystal violet (Wako, Osaka, Japan) in $0.5 \%$ methanol. The number of colonies was determined by a colony counter and software (Microtec Nition, Chiba, Japan).

Cell proliferation assay. We used BrdU assays [Cell Proliferation ELISA, BrdU (colorimetric); Roche, Tokyo, Japan] to assess cell proliferation. LLC cells $\left(3.0 \times 10^{3}\right.$ cells) were incubated in 96 -well plates. The next day, the medium was replaced by complete medium containing the indicated concentrations of BPS, and LLC cells were incubated for 3 days. After a 3-day BPS treatment, the BrdU assay was performed according to the manufacturer's protocol. BrdU was added in the medium, and LLC cells were incubated for $2 \mathrm{~h}$. The BrdU-uptake in the treated cells was assessed using a microplate luminometer (Thermo Fisher Scientific, Waltham, MA, USA).

Antibody array. LLC cells $\left(2.5 \times 10^{3}\right.$ cells) were incubated in $100 \mathrm{~mm}$ dishes for $24 \mathrm{~h}$. Subsequently, the growth medium was changed to complete medium containing 0 or $10 \mathrm{nM}$ BPS. Treated cells were incubated under the normoxic condition for 4 days. After incubation, we measured the cytokine spectrum in the supernatants using the Proteome Profiler ${ }^{\mathrm{TM}}$ Mouse Angiogenesis Array kit (R\&D Systems, Minneapolis, MN, 
A

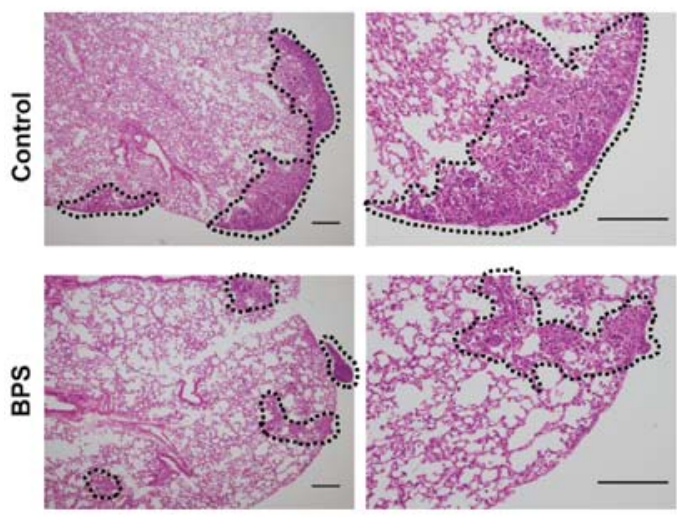

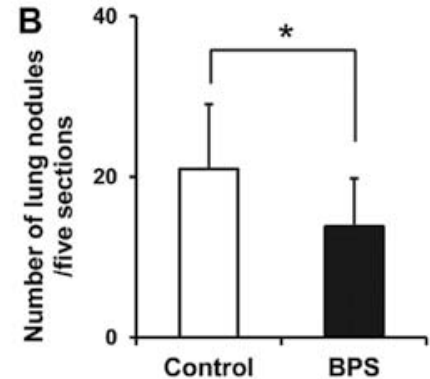

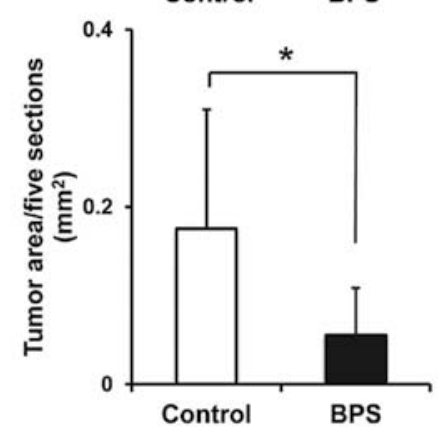

Figure 1. Beraprost sodium (BPS) suppresses lung metastasis. (A) Representative images of hematoxylin and eosin (H\&E) staining of the lung sections of control- (upper) and BPS-treated (lower) groups. Right-hand images are enlarged view of left-hand images. Scale bar, $200 \mu \mathrm{m}$. The lung metastasis area is defined with a black dashed line. (B) Upper: Number of lung nodules in H\&E-stained lung sections in control (N=5) and BPS-treated (N=5) groups. Lower: Size of lung nodules of H\&E-stained lung sections in control $(\mathrm{N}=5)$ and BPS-treated $(\mathrm{N}=5)$ groups. Error bars represent $\mathrm{SEM}$; asterisks denote significance $\left({ }^{*} \mathrm{p}<0.05\right)$.

USA), which detects 53 cytokines, chemokines, and growth factors simultaneously. Array membranes were processed following the manufacturer's recommendations. The signal intensity was measured on the LAS-3000 luminescence detector, and the resulting images were analyzed using Multi Gauge (Version 2.2; both from Fujifilm, Tokyo, Japan). To compare the luminescence intensities of the samples, we subtracted the background staining and normalized the data to the positive controls on the same membrane.

Statistical analysis. The measurements are presented as means \pm SEM. Results were analyzed by Student's t-test using Microsoft Excel. Two-sided p $<0.05$ was considered to be statistically significant.

\section{Results}

BPS treatment reduces lung metastasis. To evaluate the effect of BPS on lung metastasis, we employed an experimental lung metastasis model. After tumor cell inoculation, mice were treated with BPS for 3 weeks; then they were sacrificed, and lung metastases were counted in the H\&E-stained lung sections. In control groups, tumors with wide-spread pleural dissemination of colonized metastases were observed, while tumors with randomly clustered small metastatic nodules were observed in the BPS-treated group (Fig. 1A). The median number of metastatic nodules in the BPS-treated groups was significantly reduced compared with that in the control group (13.8 vs. 21.0, respectively, $\mathrm{p}<0.05$ ) (Fig. 1B). The median area of metastatic nodules in BPS-treated groups was significantly smaller than that in control groups $\left(0.06\right.$ and $0.18 / \mathrm{mm}^{2}$, respectively, $\mathrm{p}<0.05$ ) (Fig. 1B). These results suggest that administration of BPS significantly reduced the number of lung metastases in our mouse lung metastasis model.
BPS enhances pericyte and endothelial interaction in tumor microvasculature. Next, to evaluate vascular maturation through endothelial and pericyte interaction, we analyzed the structure of tumor blood vessels in the mouse metastatic tumors using scanning electron microscopy. In the BPS-treated group, pericyte bodies (green) attached to endothelial capillary tubes (red) along with processes, and the diameters of tumor blood vessels were decreased, while in the control group, pericytes were absent or loosely connected (Fig. 2A).

To evaluate the effects of BPS on tumor angiogenesis, including pericyte association at the metastatic site, pericytes $\left(\alpha-\mathrm{SMA}^{+}\right.$or $\mathrm{NG}^{+}$cells) and endothelial cells (Endomucin ${ }^{+}$cells) in the metastatic tumor site were analyzed by immunofluorescence (Figs. 2B and 3A). In the control group, $\alpha-\mathrm{SMA}^{+}$or $\mathrm{NG}^{+}$cells were mostly located randomly in the metastatic tumor sites, and they did not colocalize with Endomucin $^{+}$cells (Figs. 2B and 3A), while in the BPS-treated group, $\alpha-\mathrm{SMA}^{+}$or $\mathrm{NG}^{+}$cells coexisted regularly beside Endomucin ${ }^{+}$cells, and most of these cells were merged with Endomucin $^{+}$cells (Figs. 2B and 3A), which revealed that the number of mature pericytes had increased, and moreover, the number of endothelial-attached pericytes was increased compared with that in the control group (Figs. 2C and 3B). These results suggested that BPS strongly enhanced pericyte and endothelial interaction in the tumor microvasculature.

BPS induces vascular functional maturation in metastatic tumors. We hypothesized that functionally mature vasculature without hypoxic regions abrogate tumor metastasis because pericyte-covered endothelial cells are considered 'mature vasculature,' which is rarely observed in the tumor area. In order to evaluate the tumor vascular maturation, we measured hypoxia levels in the metastatic tumors by immunohistochemistry using pimonidazole as a hypoxia marker. Pimonidazole stained the 

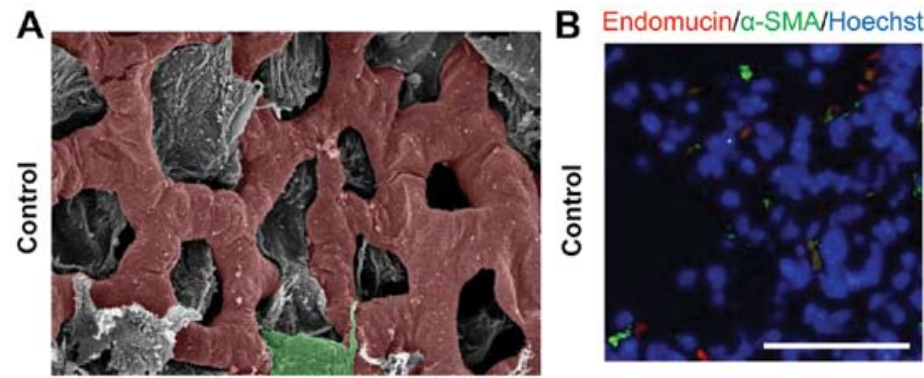

C
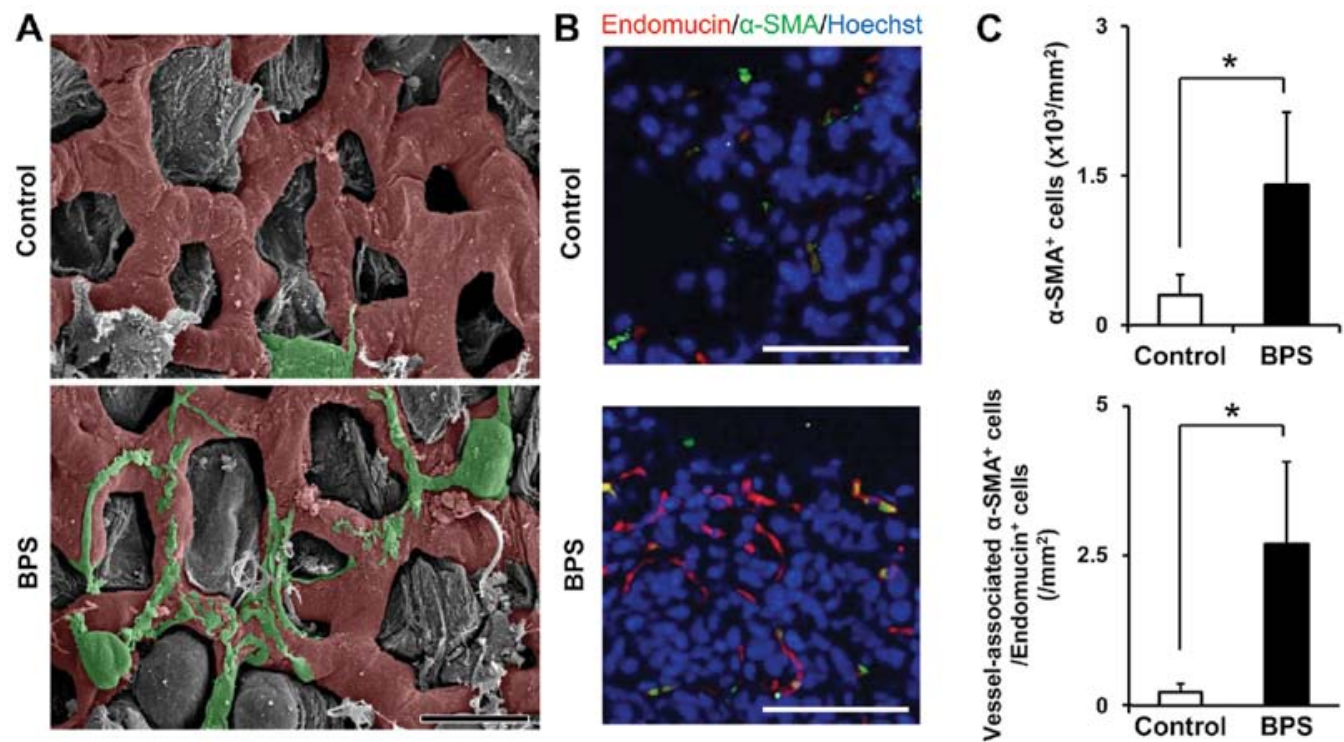

Figure 2. Beraprost sodium (BPS) increased vessels covered with pericytes in tumors. (A) Potassium hydroxide (KOH)-digested lung tissues of control (upper) and BPS-treated (lower) groups were viewed with a scanning electron microscope. As a reflection of their association with tumor vessels, pericyte cell bodies (green) attached to endothelial capillary tubes (red) increased in the BPS-treated group. In addition, tumor vessels covered with pericyte processes (green) increased in the BPS-treated group. Scale bar, $10 \mu \mathrm{m}$. (B) Representative images of tumor sections of control (upper) and BPS-treated (lower) groups immunolabeled for Endomucin (red) and $\alpha$-SMA (green). Hoechst stain, nuclei. Scale bar, $50 \mu \mathrm{m}$. (C) Upper: $\alpha$-SMA ${ }^{+}$cells/tumor area in control (N=5) and BPS-treated $(\mathrm{N}=5)$ groups. Lower: Vessel-associated $\alpha-\mathrm{SMA}^{+}$cells/Endomucin ${ }^{+}$cells/tumor area in control $(\mathrm{N}=5)$ and $\mathrm{BPS}-$ treated $(\mathrm{N}=5)$ groups. Error bars represent SEM; asterisks denote significance $\left({ }^{*} \mathrm{p}<0.05\right)$.

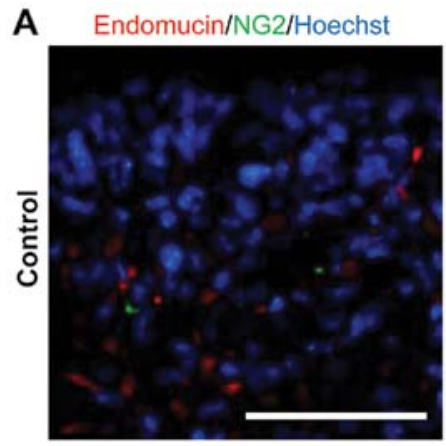

B
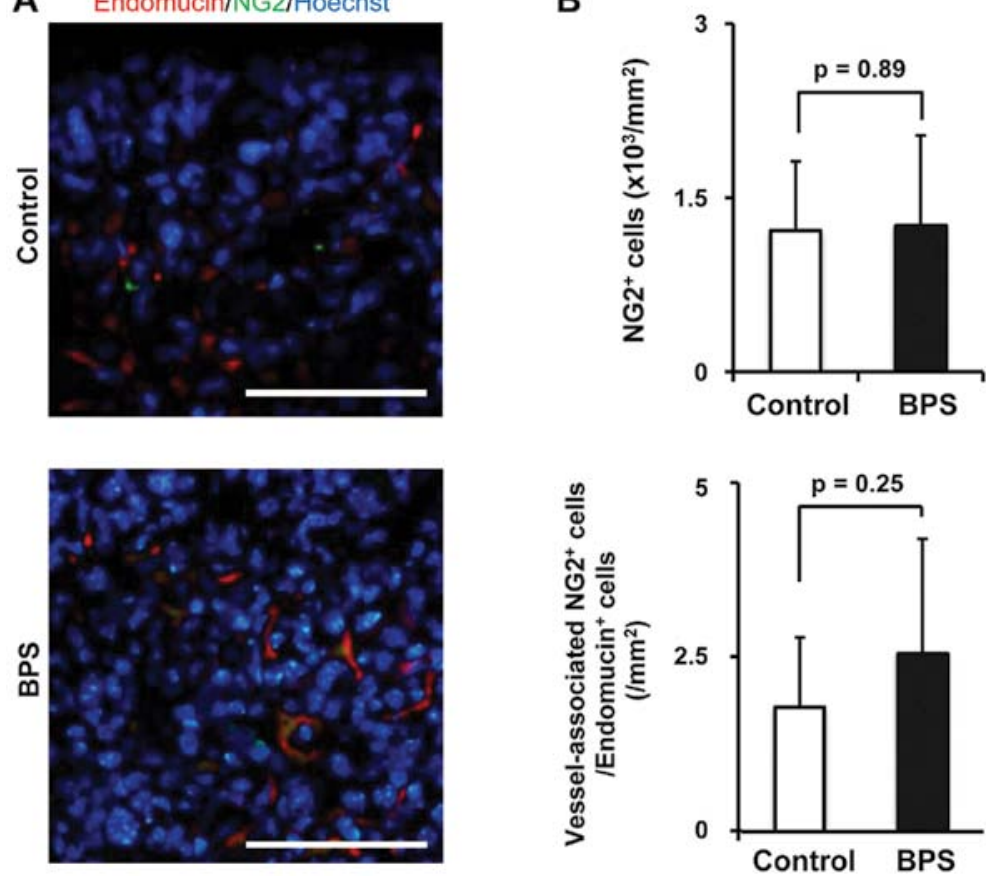

Figure 3. Immunohistochemistry of mouse lung metastasis models. (A) Representative images of tumor sections of control (upper) and beraprost sodium (BPS)-treated (lower) groups immunolabeled for Endomucin (red) and NG2 (green). Hoechst, nuclei. Scale bar, $50 \mu \mathrm{m}$. (B) Upper: NG2 ${ }^{+}$cells/tumor area in control $(\mathrm{N}=5)$ and BPS-treated $(\mathrm{N}=5)$ groups. Lower: Vessel-associated $\mathrm{NG}^{+}$cells/Endomucin ${ }^{+}$cells/tumor area in control $(\mathrm{N}=5)$ and $\mathrm{BPS}$-treated $(\mathrm{N}=5)$ groups. Error bars represent SEM.

inside of the metastatic tumors in the control group widely, while it stained scattered and diminished areas in the BPS-treated group (Fig. 4A). Pimonidazole staining per tumor area in the BPS-treated group was $0.5 \%$, while in the control group it was $1.9 \%$. The area stained by pimonidazole was significantly decreased in the BPS-treated group $(\mathrm{p}<0.05)$ (Fig. 4B). These results suggested that BPS induced maturation of vascular function in metastatic tumors.

Antitumor effects of BPS against cancer cells. Because a direct inhibitory effect of a $\mathrm{PGI}_{2}$ analog on tumor cells, has been reported (25-27), we evaluated the antitumor effects of BPS 

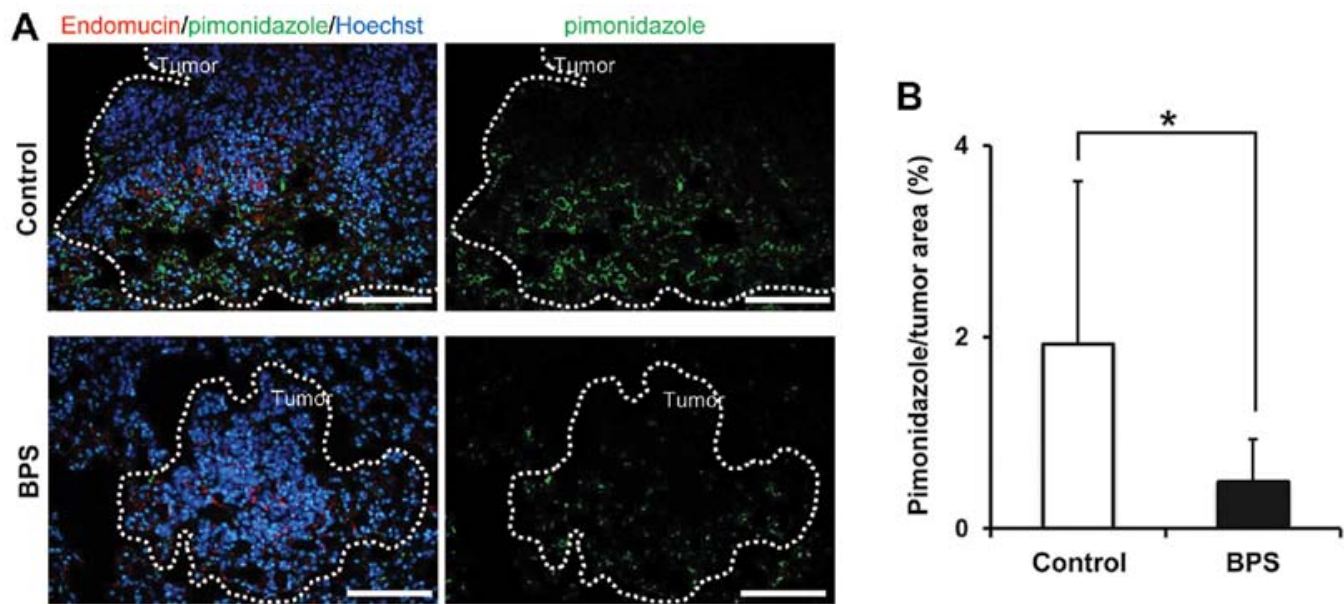

Figure 4. Beraprost sodium (BPS) decreased the hypoxic area in tumors. (A) Representative images of tumor sections of control (upper) and BPS-treated (lower) groups immunolabeled for Endomucin (red) and pimonidazole adducts (green). Hoechst, nuclei. Scale bar, $100 \mu \mathrm{m}$. (B) Hypoxic area/tumor area (\%) in control $(\mathrm{N}=2)$ and BPS-treated $(\mathrm{N}=2)$ groups. Error bars represent $\mathrm{SEM}$; asterisks denote significance $(\mathrm{p}<0.05)$.
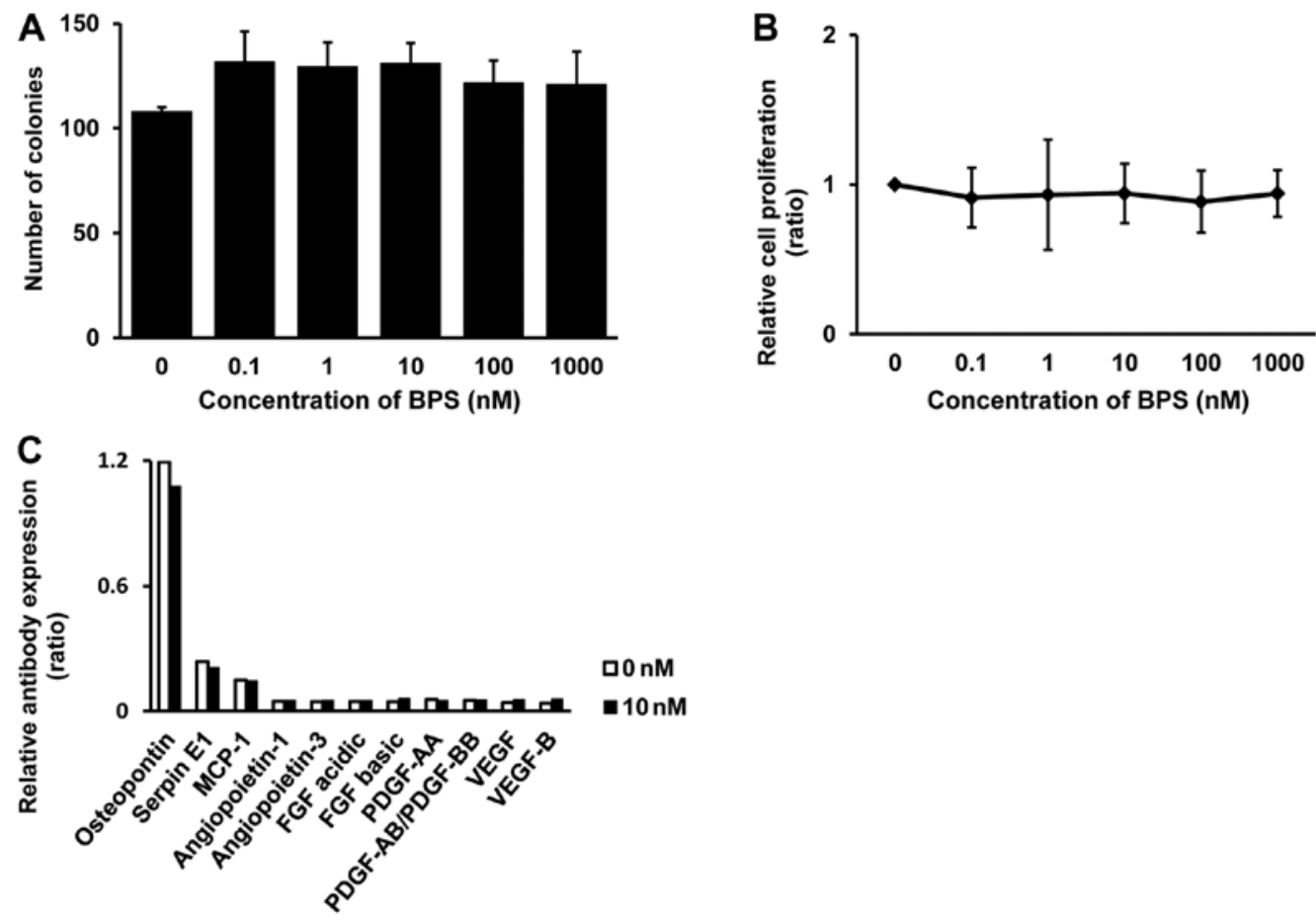

Figure 5. Direct antitumor effects of beraprost sodium (BPS) on Lewis lung carcinoma (LLC) cells. (A) Clonogenic growth assay of LLC cells treated with BPS BPS does not affect colony formation of cultured LLC cells. Cells were treated with indicated concentrations of BPS for 10 days, and the number of colonies was determined by a colony counter and software. Mean values were calculated from three independent experiments. Error bars represent SEM. (B) Cell proliferation assay of LLC cells treated with BPS. BPS does not affect the proliferation of cultured LLC cells. Cells were treated with the indicated concentrations of BPS for $72 \mathrm{~h}$, and proliferation was measured by BrdU assay. Mean values were obtained from three independent experiments. The values are shown as a ratio. Error bars represent SEM. (C) Angiogenesis antibody array of supernatant of BPS-treated LLC cells. Eleven factors were selected from 53 cytokines, chemokines, and growth factors. BPS does not affect the production of angiogenic factors secreted by LLC cells. Cells were treated with the indicated concentrations of BPS for $96 \mathrm{~h}$, and the production of angiogenic factors was measured by an angiogenesis antibody array. The values are shown as a ratio.

on LLC cells. The cell growth was assessed by the BrdU cell growth assay or clonogenic assay (Fig. 5A and B). In our results, BPS did not inhibit tumor growth. To examine the autocrine factors related to tumor angiogenesis, we analyzed the effects of conditioned media with or without BPS on LLC cells using an antibody array that simultaneously detected the relative concentrations of 53 angiogenesis-related proteins (Fig. 5C). In this assay, osteopontin, serpin E1, and MCP-1 were elevated in both BPS-treated and untreated groups, but the change in these factors were not significant. Based on these results, BPS did not affect LLC cell growth directly.

\section{Discussion}

In the present study, the number of lung metastases was significantly reduced by BPS treatment in our mouse model. 
Since the first report from Honn and colleagues demonstrating that $\mathrm{PGI}_{2}$ and its analogs strongly reduced the number of lung metastases (3), studies of the $\mathrm{PGI}_{2}$ effect on metastasis have been repeated using a wide variety of tumor cell lines (4-15). Because multistep processes of metastasis formation are responsible for the tumor spread, the effect of BPS on tumors and the tumor microenvironment needs to be analyzed. Most studies have examined: i) tumor cell-induced platelet aggregation and its inhibition by $\mathrm{PGI}_{2}(5,6,28-30)$; ii) prevention of endothelial cell retraction (31-33); iii) modulation of immune systems (4,7); or iv) direct inhibitory effects on tumor cells (25-27). However, the mechanisms of tumor vessel maturation by $\mathrm{PGI}_{2}$ was not previously examined.

In this study, we demonstrated that BPS strongly enhanced pericyte and endothelial interaction in the tumor microvasculature, which is a novel anti-metastatic mechanism of a $\mathrm{PGI}_{2}$ analog. The present results suggested that BPS induced structural changes in tumor vessels and led to endothelial maturation, which is consistent with our previous results (34). Consequently, tumor vessel maturation was induced, and hypoxia levels in the metastatic tumors decreased, resulting in BPS-induced vascular normalization in the tumor microenvironment. These results seem paradoxical because improving circulation in the tumor leads to tumor shrinkage, but clinically used anti-angiogenic therapies that successfully target tumor vessels are believed to increase microenvironment-induced tumor shrinkage. Bevacizumab, an anti-angiogenic drug, is now used in combination with cytotoxic agent for vascular normalization.

In the analysis of immunohistochemistry, $\alpha-\mathrm{SMA}^{+}$cells merged with Endomucin ${ }^{+}$cells significantly increased in the BPS-treated group (Fig. 2C), while $\mathrm{NG} 2^{+}$cells merged with Endomucin ${ }^{+}$cells did not significantly increase in the BPS-treated group (Fig. 3B). This result seems to be inconsistent. However, in general, it is known that $\alpha$-SMA expresses in more mature status of pericytes than NG2 (35), and BPS induced more mature pericytes in this study. The number of endothelial cells in the tumors increased in the BPS-treated group with or without pericytes (data not shown). These results indicate that BPS promotes the maturation of tumor blood vessels.

Finally, to rule out the possibility of a direct tumor effect of BPS on LLC cells, we investigated tumor growth inhibition by treatment of cultured cells with BPS at concentrations up to $1 \mu \mathrm{M}$. The angiogenic factors produced by LLC cells themselves were not changed. These results suggested that BPS did not affect tumors directly, but affected the tumor microenvironment.

Altering the tumor microenvironment by addition of $\mathrm{PGI}_{2}$ analogs that affect endothelium-pericyte interaction may yield strategies for targeted angiogenesis therapies. However, additional clinical studies are needed to clarify the potential benefits and risks associated with anti-metastatic treatment by $\mathrm{PGI}_{2}$ analogs.

\section{Acknowledgements}

The authors thank Dr Fumitaka Ushikubi for advice and kindly providing experimental equipment. This study was partially supported by funding from the JSPS Grant-in-Aid for Scientific Research (C) (KAKENHI) Grant no. 20590910.

\section{References}

1. Turner EC, Mulvaney EP, Reid HM and Kinsella BT: Interaction of the human prostacyclin receptor with the PDZ adapter protein PDZK1: role in endothelial cell migration and angiogenesis. Mol Biol Cell 22: 2664-2679, 2011.

2. Zhu W, Saddar S, Seetharam D, et al: The scavenger receptor class B type I adaptor protein PDZK1 maintains endothelial monolayer integrity. Circ Res 102: 480-487, 2008.

3. Honn KV, Cicone B and Skoff A: Prostacyclin: a potent antimetastatic agent. Science 212: 1270-1272, 1981.

4. Gorelik E, Bere WW and Herberman RB: Role of NK cells in the antimetastatic effect of anticoagulant drugs. Int J Cancer 33: 87-94, 1984.

5. Menter DG, Harkins C, Onoda J, et al: Inhibition of tumor cell induced platelet aggregation by prostacyclin and carbacyclin: an ultrastructural study. Invasion Metastasis 7: 109-128, 1987.

6. Niitsu Y, Ishigaki S, Kogawa K, et al: Effect of combined administration of a prostacyclin analogue and adriamycin against the artificial metastasis of Meth A cell. Invasion Metastasis 8: 57-72, 1988.

7. Sava G, Perissin L, Zorzet S, Piccini P and Giraldi T: Antimetastatic action of the prostacyclin analog iloprost in the mouse. Clin Exp Metastasis 7: 671-678, 1989.

8. Honn KV: Inhibition of tumor cell metastasis by modulation of the vascular prostacyclin/thromboxane A2 system. Clin Exp Metastasis 1: 103-114, 1983.

9. Karpatkin S, Ambrogio C and Pearlstein E: Lack of effect of in vivo prostacyclin on the development of pulmonary metastases in mice following intravenous injection of CT26 colon carcinoma, Lewis lung carcinoma, or B16 amelanotic melanoma cells. Cancer Res 44: 3880-3883, 1984.

10. Mahalingam M, Ugen KE, Kao KJ and Klein PA: Functional role of platelets in experimental metastasis studied with cloned murine fibrosarcoma cell variants. Cancer Res 48: 1460-1464, 1988.

11. Lapis K, Timár J, Pápay J, Paku S, Szende B and Ladányi A: Experimental metastasis inhibition by pretreatment of the host. Arch Geschwulstforsch 60: 97-102, 1990.

12. Kato S, Kobari M, Matsuno S and Sato T: Inhibitory effect of anti-platelet prostaglandin on liver metastasis of hamster pancreatic cancer. Nihon Geka Gakkai Zasshi 90: 745-752, 1989 (In Japanese).

13. Schwalke MA, Tzanakakis GN and Vezeridis MP: Effects of prostacyclin on hepatic metastases from human pancreatic cancer in the nude mouse. J Surg Res 49: 164-167, 1990.

14. Tzanakakis GN, Agarwal KC and Vezeridis MP: Inhibition of hepatic metastasis from a human pancreatic adenocarcinoma (RWP-2) in the nude mouse by prostacyclin, forskolin, and ketoconazole. Cancer 65: 446-451, 1990.

15. Costantini V, Fuschiotti P, Giampietri A, et al: Effects of a stable prostacyclin analogue on platelet activity and on host immunocompetence in mice. Prostaglandins 39: 581-599, 1990.

16. Pasqualini R, Arap W and McDonald DM: Probing the structural and molecular diversity of tumor vasculature. Trends Mol Med 8: 563-571, 2002.

17. Minami Y, Sasaki T, Kawabe J and Ohsaki Y: Accessory cells in tumor angiogenesis - tumor-associated pericytes. In: Research Directions in Tumor Angiogenesis. Chai J (ed). InTech, Croatia, pp73-89, 2013.

18. Morikawa S, Baluk P, Kaidoh T, Haskell A, Jain RK and McDonald DM: Abnormalities in pericytes on blood vessels and endothelial sprouts in tumors. Am J Pathol 160: 985-1000, 2002.

19. O'Keeffe MB, Devlin AH, Burns AJ, et al: Investigation of pericytes, hypoxia, and vascularity in bladder tumors: association with clinical outcomes. Oncol Res 17: 93-101, 2008.

20. Stefansson IM, Salvesen HB and Akslen LA: Vascular proliferation is important for clinical progress of endometrial cancer. Cancer Res 66: 3303-3309, 2006.

21. Yonenaga Y, Mori A, Onodera H, et al: Absence of smooth muscle actin-positive pericyte coverage of tumor vessels correlates with hematogenous metastasis and prognosis of colorectal cancer patients. Oncology 69: 159-166, 2005.

22. Xian X, Håkansson J, Ståhlberg A, et al: Pericytes limit tumor cell metastasis. J Clin Invest 116: 642-651, 2006.

23. Kawabe J, Yuhki K, Okada M, et al: Prostaglandin $\mathrm{I}_{2}$ promotes recruitment of endothelial progenitor cells and limits vascular remodeling. Arterioscler Thromb Vasc Biol 30: 464-470, 2010. 
24. Ushiki $\mathrm{T}$ and Murakumo M: Scanning electron microscopic studies of tissue elastin components exposed by a $\mathrm{KOH}$-collagenase or simple $\mathrm{KOH}$ digestion method. Arch Histol Cytol 54: 427-436, 1991.

25. Tennis MA, Van Scoyk M, Heasley LE, et al: Prostacyclin inhibits non-small cell lung cancer growth by a frizzled 9-dependent pathway that is blocked by secreted frizzled-related protein 1 . Neoplasia 12: 244-253, 2010.

26. Honn KV and Meyer J: Thromboxanes and prostacyclin: positive and negative modulators of tumor growth. Biochem Biophys Res Commun 102: 1122-1129, 1981.

27. Tang DG, Grossi IM, Chen YQ, Diglio CA and Honn KV: 12(S)-HETE promotes tumor-cell adhesion by increasing surface expression of alpha $\mathrm{V}$ beta 3 integrins on endothelial cells. Int $\mathrm{J}$ Cancer 54: 102-111, 1993.

28. Honn KV, Busse WD and Sloane BF: Prostacyclin and thromboxanes. Implications for their role in tumor cell metastasis. Biochem Pharmacol 32: 1-11, 1983.

29. Menter DG, Onoda JM, Moilanen D, Sloane BF, Taylor JD and Honn KV: Inhibition by prostacyclin of the tumor cell-induced platelet release reaction and platelet aggregation. J Natl Cancer Inst 78: 961-969, 1987.
30. Menter DG, Onoda JM, Taylor JD and Honn KV: Effects of prostacyclin on tumor cell-induced platelet aggregation. Cancer Res 44: 450-456, 1984.

31. Honn KV, Tang DG, Grossi IM, et al: Enhanced endothelial cell retraction mediated by $12(\mathrm{~S})$-HETE: a proposed mechanism for the role of platelets in tumor cell metastasis. Exp Cell Res 210: 1-9, 1994.

32. Honn KV, Grossi IM, Diglio CA, Wojtukiewicz M and Taylor JD: Enhanced tumor cell adhesion to the subendothelial matrix resulting from 12(S)-HETE-induced endothelial cell retraction. FASEB J 3: 2285-2293, 1989.

33. Honn KV, Tang DG, Grossi I, et al: Tumor cell-derived 12(S)-hydroxyeicosatetraenoic acid induces microvascular endothelial cell retraction. Cancer Res 54: 565-574, 1994.

34. Aburakawa Y, Kawabe J, Okada M, et al: Prostacyclin stimulated integrin-dependent angiogenic effects of endothelial progenitor cells and mediated potent circulation recovery in ischemic hind limb model. Circ J 77: 1053-1062, 2013

35. Cipriani P, Marrelli A, Benedetto PD, et al: Scleroderma Mesenchymal Stem Cells display a different phenotype from healthy controls; implications for regenerative medicine. Angiogenesis 16: 595-607, 2013. 